\title{
Analysis of flash flood scenarios in an urbanized catchment using a two-dimensional hydraulic model
}

\author{
F. DOTTORI ${ }^{1}$, F. GRAZZINI ${ }^{2}$, M. DI LORENZO ${ }^{2}$, A. SPISNI ${ }^{2} \&$ F. TOMEI ${ }^{2}$ \\ 1 Department of Biological, Geological and Environmental Sciences, University of Bologna. Now at Institute for \\ Environment and Sustainability, Joint Research Centre, European Commission, Via E. Fermi 2749, TP261, \\ 21027 Ispra (VA), Italy \\ francesco.dottori@jrc.ec.europa.eu \\ 2 Hydrometeorological and Climate Service, ARPA Emilia-Romagna, viale Silvani 6, 40122 Bologna, Italy
}

\begin{abstract}
In Italy, growing urbanization is leading to a higher risk of flooding of small water courses, especially in steep catchments of limited area, where severe flash flood events can occur. The assessment of flash flood hazard requires new modelling tools that can reproduce both the rainfall-runoff processes in the catchment, and the flow processes in the drainage network. In this paper we propose the use of a simple two-dimensional hydraulic model for analysing a flood scenario in a small valley within the urban area of the city of Bologna, Italy. Historically this area has been prone to severe flood events, the most recent of which occurred in 1955 and 1932. Since then there has been a significant increase in urbanization of the lower portion of the catchment, while the natural stream bed has been partially replaced by a culvert. The two-dimensional hydraulic model was therefore applied at catchment scale, in order to simulate the possible effects of historical scenarios in the present catchment configuration. Rainfall and runoff data measured during recent rainfall events were used to calibrate model parameters. Model results show that the current culvert section would be insufficient to drain the runoff produced by intense rainfall events, with potential inundation of surrounding urban areas.
\end{abstract}

Key words flash floods; two-dimensional hydraulic model; urban areas; land-use change

\section{INTRODUCTION}

The risk of flooding of small water courses is a major problem in several urban areas in Italy. The constant growth of urbanization, with the consequent decrease of soil permeability and loss of space for river and stream beds, is leading to increased flood hazard and vulnerability (Hapuarachchi et al. 2011). In such conditions, severe rainfall events over steep catchments of limited area can produce dramatic consequences, such as occurred in November 2011, when the city of Genoa and several towns and villages in northern Italy were hit by catastrophic flash floods. In addition, ongoing climate changes are likely to increase the occurrence of severe precipitation events, thus increasing flash flood hazard.

Despite its relevance, the risk flooding of small water courses in urban areas is often underestimated and few measures are taken for prevention and mitigation. For this purpose, the use of innovative hydrological and hydraulic models may be useful for analysing the complex rainfallrunoff processes in the catchment and the consequent flow processes in the drainage network, and for providing a quantification of the hazard and vulnerability components of flood risk. Here, we propose the use of a simple two-dimensional (2D) hydraulic model to simulate a reference flood scenario in an urbanized small catchment, considering historical intense rainfall events and analysing the possible effects in the present catchment configuration.

\section{DATA AND METHODS}

\section{The study area}

This study focuses on the catchment of a small stream (the Ravone) located in the municipality of Bologna, in northern Italy (Fig. 1(a)). The upper part of the catchment is characterized by hills and steep slopes, with a prevalent vegetation cover (grass, shrubs, and forest) and partial urbanization in the stream valley. In contrast, the lower portion is flat and densely urbanized, the drainage network is mainly artificial, and the main water course flows in a culvert underneath the city's urban area before joining the Reno River. The natural reach length is approximately $4 \mathrm{~km}$, the culvert reach length is $6 \mathrm{~km}$, and the catchment area extends for about $7 \mathrm{~km}^{2}$. In this paper, only the upper part of the Ravone catchment is analysed, as data describing the drainage network in the urban area were not available. 
Historical and recent records report that the urban areas of Bologna located downstream of the high and are prone to severe flood events caused by small water courses. The most severe event occurred in 1932, when rainfall of $134 \mathrm{~mm}$ within a few hours caused flooding of a large urban area, including a portion of the Ravone catchment. Another severe flood event occurred in the Bologna area in 1955, while in 2002 a further flood event affected several small municipalities nearby. In all of these cases, the recorded hourly peak intensity exceeded $50 \mathrm{~mm} / \mathrm{h}$.

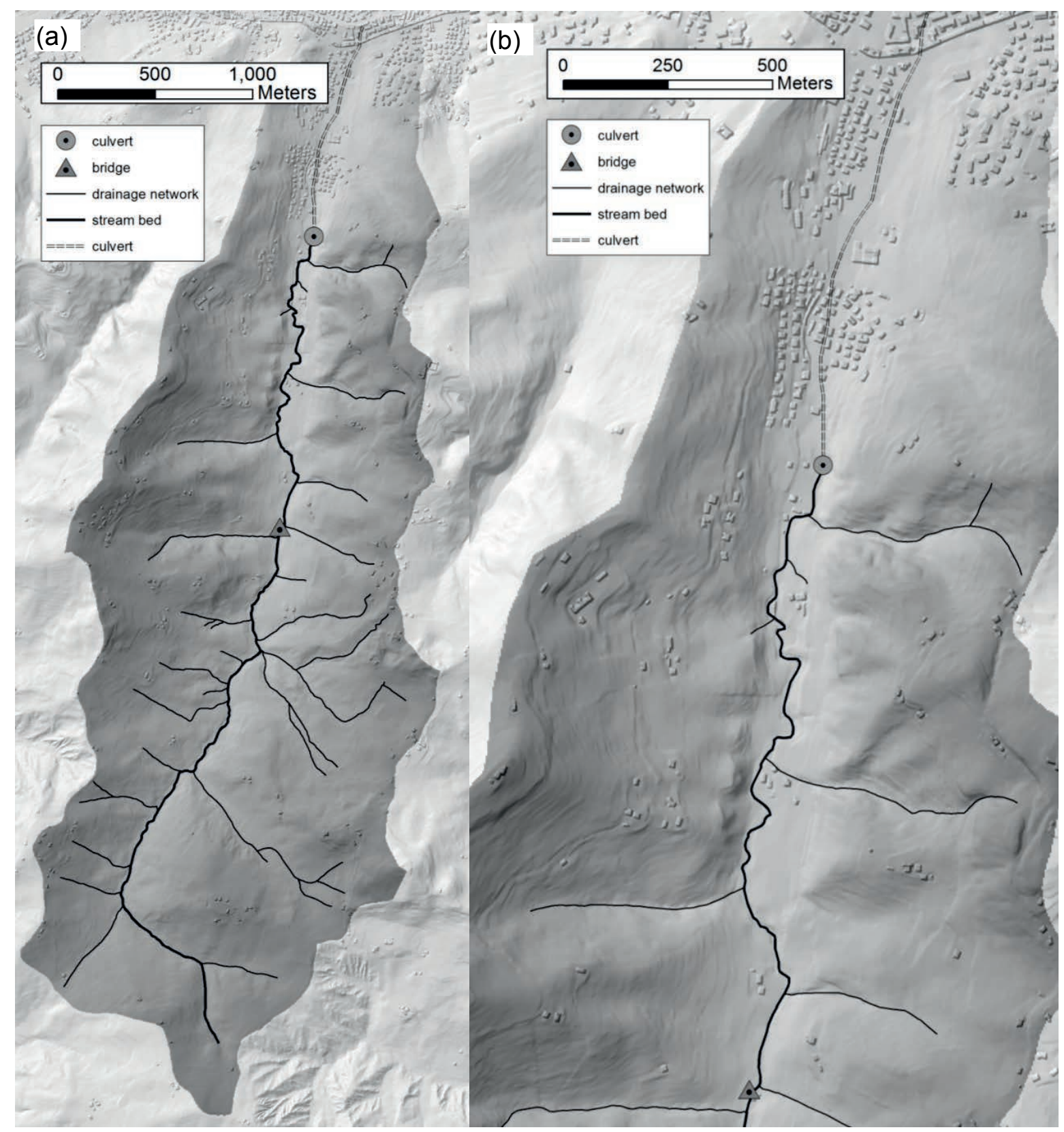

Fig. 1 (a) Digital elevation model (DEM) and drainage network of the upper portion of the Ravone catchment (dark grey area). (b) Detailed view of the urbanized portion of the study area. The culvert reach is indicated by a dashed line. The map includes the location of the culvert and bridge sections, where observations of water depth are available for a rainfall event that occurred on 5 April 2013.

It is worth noting that at the time of the 1932 and 1955 events, urbanization of the areas affected by flooding was still limited, and the stream beds were in a relatively natural condition. Since then, urbanization of the areas downstream of the highland has significantly increased, while most of the drainage network has been partially replaced by culverts, acting as collectors for the surface drainage 
system. As such, the vulnerability of these areas has increased, as demonstrated by the severe damages caused by the 2002 event. At the same time, the awareness of risk amongst the population living there has effectively decreased, because the water courses are no longer visible.

\section{Modelling approach}

The study of flood hazard in small urbanized catchments by means of hydrological and hydraulic models is indeed challenging (Hapuarachchi et al. 2011). The adopted modelling tools should be able to reproduce both rainfall-runoff processes at catchment scale, and flow processes along the drainage network, including possible flooding processes and the influence of hydraulic structures and buildings. Given the complex interactions between these processes, in this study we chose to adopt a single model instead of combining separated hydrological and hydraulic models. We therefore apply a simple 2D hydraulic model, called CA2D (Dottori and Todini 2011), which has already been successfully applied for reproducing flow in urban areas and over steep slopes (Dottori and Todini 2013), and for simulating rainfall-runoff at catchment scale. A similar approach was recently used by Costabile et al. (2013) to simulate real events that occurred in a mountain subcatchment of the Reno River, $50 \mathrm{~km}$ from Bologna.

\section{Data collection}

For the application of the CA2D (Cellular Automata Two-Dimensional) model, a digital elevation model (DEM) of the study area, at $2 \mathrm{~m}$ resolution, is available. The DEM includes all the buildings located in the study area, which are represented as blocks using roof-top height (Fig. 1). In addition, the available topographic dataset includes maps of land-use, surface drainage network and soils.

Rainfall data are available from a meteorological station located near (i.e. approximately $500 \mathrm{~m}$ from) the catchment urban area. To integrate the available dataset, in 2012 a second raingauge was installed at the catchment's upstream end.

To obtain the model computational grid, the original DEM was resampled to a $4 \mathrm{~m}$ resolution, in order to provide acceptable model run times while accurately reproducing the stream bed and the urban topography. The stream-bed, not included in the original data, has been manually inserted using geometry and altimetry data from a number of cross-section surveys carried out for the present study. The culvert section has been modelled within the grid as an outlet with a varying boundary condition (either weir flow or pressurized flow according to local water depth). It is worth noting that, coinciding with the culvert entry, there is an abrupt reduction of the stream cross-section, which changes from a $4 \mathrm{~m}$ wide, $3 \mathrm{~m}$ high trapezoidal section upstream, to a $2.5 \times 2.4 \mathrm{~m}$ rectangular section downstream.

\section{MODEL SIMULATIONS}

\section{Calibration scenario}

The model has been calibrated through the simulation of a rainfall event that occurred on 5 April 2013. Despite the moderate amount of total rainfall ( $20 \mathrm{~mm}$ over 6 hours, as reported in Fig. 2 ), the consequent runoff was relatively large, due to the soil saturation determined by significant rainfalls in the previous months. In particular, a visual inspection of water depths immediately upstream of the culvert section during the event allowed estimation of peak depth of around 1.9 to $2.0 \mathrm{~m}$, i.e. only $40-50 \mathrm{~cm}$ below the culvert ceiling. The peak value was observed approximately five hours after the beginning of rainfall. In a bridge section located $1.5 \mathrm{~km}$ upstream (Fig. 1(b)) the observation of water marks after the flood peak indicated a peak depth of $1 \mathrm{~m}$.

The available measured rainfall and the flow depth observations were used to set up the model configuration and calibrate the parameters. As measurements carried out during the event did not show differences between the two available raingauges, the rainfall was assumed to be uniform over the catchment. Given the saturated condition of catchment soil and surface, the effects of interception, infiltration and surface storage were assumed to be negligible. Roughness coefficients 
have been assigned to each grid cell according to morphological and land-use information, using the Manning coefficient: $0.05 \mathrm{~m}^{-1 / 3} \mathrm{~s}$ in urban areas and in cells of the main water course bed; $0.1 \mathrm{~m}^{-1 / 3} \mathrm{~s}$ in cells of the surface drainage network; $0.2 \mathrm{~m}^{-1 / 3} \mathrm{~s}$ elsewhere.

Results are summarized in Fig. 2. The maximum water depth at the culvert entry $(1.8 \mathrm{~m})$ is reached after 2.5 hours, thus considerably in advance of the observed peak. However, it should be considered that during the visual inspection it was difficult to assess the actual timing of the peak, since the flow remained significant with high depths for several hours afterwards. In addition, a concentration time of five hours seems to be not very realistic given the small extent of the catchment. On the other side, simulated peak depths are in good agreement with the observations, although with a slight underestimation at the culvert entry. Given the uncertainty of available streamflow data, this preliminary calibration of the model can be considered satisfactory.

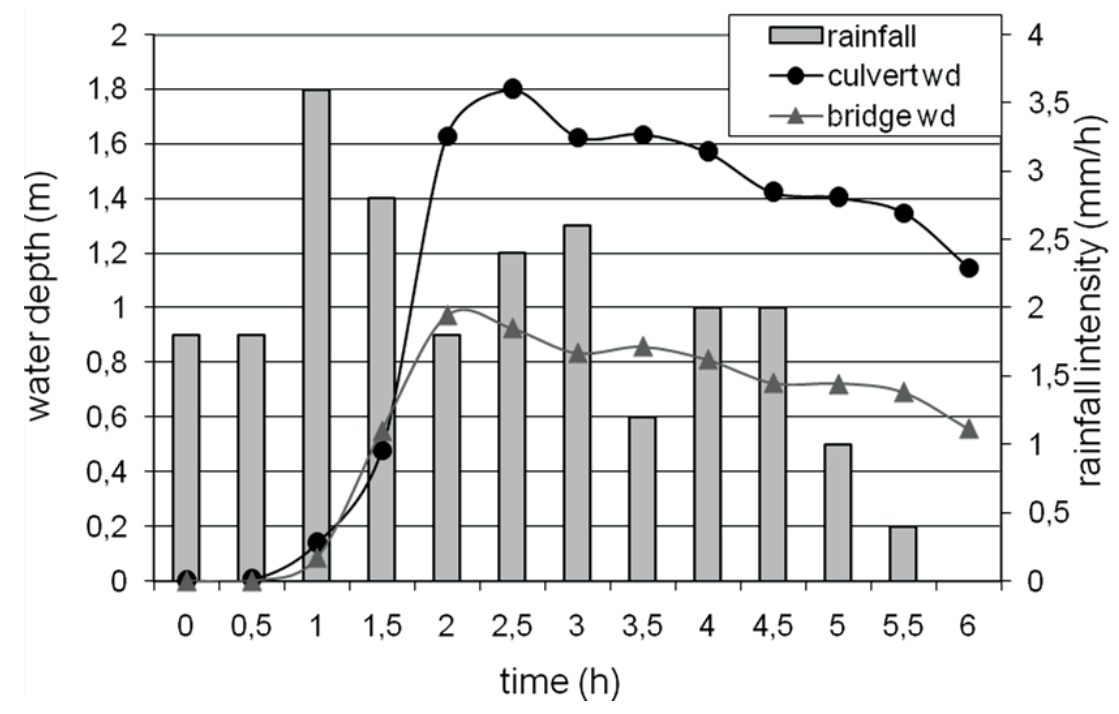

Fig. 2 Measured rainfall and simulated water depths for the event of 5 April 2013.The observed level at culvert entry peaked in a range between 1.9 and $2 \mathrm{~m}$, occurring five hours after the rainfall began.

\section{Historical scenario}

After calibration, the model was used to simulate the possible effects of a severe rainfall event, comparable with the historical events of 1932 and 1955. The selected event has a total precipitation of $70 \mathrm{~mm}$ in 2 hours, which corresponds to an estimated return period of 50 years. Rainfall intensity is variable over time and has the following distribution for each 30 minutes: $15 \mathrm{~mm}, 40 \mathrm{~mm}, 9 \mathrm{~mm}$, and $6 \mathrm{~mm}$. As in the calibration event, the rainfall was assumed to be uniform over the catchment. The effects of interception, infiltration and surface storage have been schematized considering an initial rainfall abstraction of $10 \mathrm{~mm}$, plus a further abstraction of $15 \mathrm{~mm}$ uniformly distributed in the first hour. This simple schematization has been chosen due to the absence of streamflow data for a proper calibration. However, the chosen values are comparable with standard rainfall losses given by the "Curve Number" (CN) Method for soil with a moderate permeability and vegetated land cover (Singh 2003). The roughness coefficients calibrated for the rainfall event of 5 April 2013 have also been used in this case.

The maps in Fig. 3 show the flood extent computed by the model in the urbanized portion of the catchment at different times. At $t=30$ minutes, the runoff in the Ravone is still low. However in the following minutes the discharge rapidly increases. After 50 minutes from the beginning of simulation the culvert section is no longer able to drain the runoff: the water in excess begins to flow out of the stream bed, inundating the surrounding and downstream urban area. The discharge in the stream upstream of the culvert section reaches its maximum value (above $30 \mathrm{~m}^{3} \mathrm{~s}^{-1}$ ) at $\mathrm{t}=90$ minutes and then decreases. During the flood event, water depths in flooded areas locally exceed $1.5 \mathrm{~m}$, with velocity values above $0.5 \mathrm{~m} \mathrm{~s}^{-1}$ in the steepest areas. 
When analysing these results, it should be noted that the model configuration used for this study includes some important approximations. Firstly, the culvert reach and sewer system are not reproduced, therefore all the water entering the culvert exits the domain. In the real world, however, flooding could be increased by sewer surcharge, caused by insufficient drainage of the culvert reach during peak discharge, while during the recession limb the sewer system would probably accelerate the drainage of the flooded area. In addition, flooded areas tend to drain slowly because in the current model configuration, buildings are assumed to be completely impervious to water, whereas a partial permeability should be considered (Dottori and Todini 2013). Finally, the analysed flood scenario does not take into account possible obstructions of the culvert entry due to floating debris.

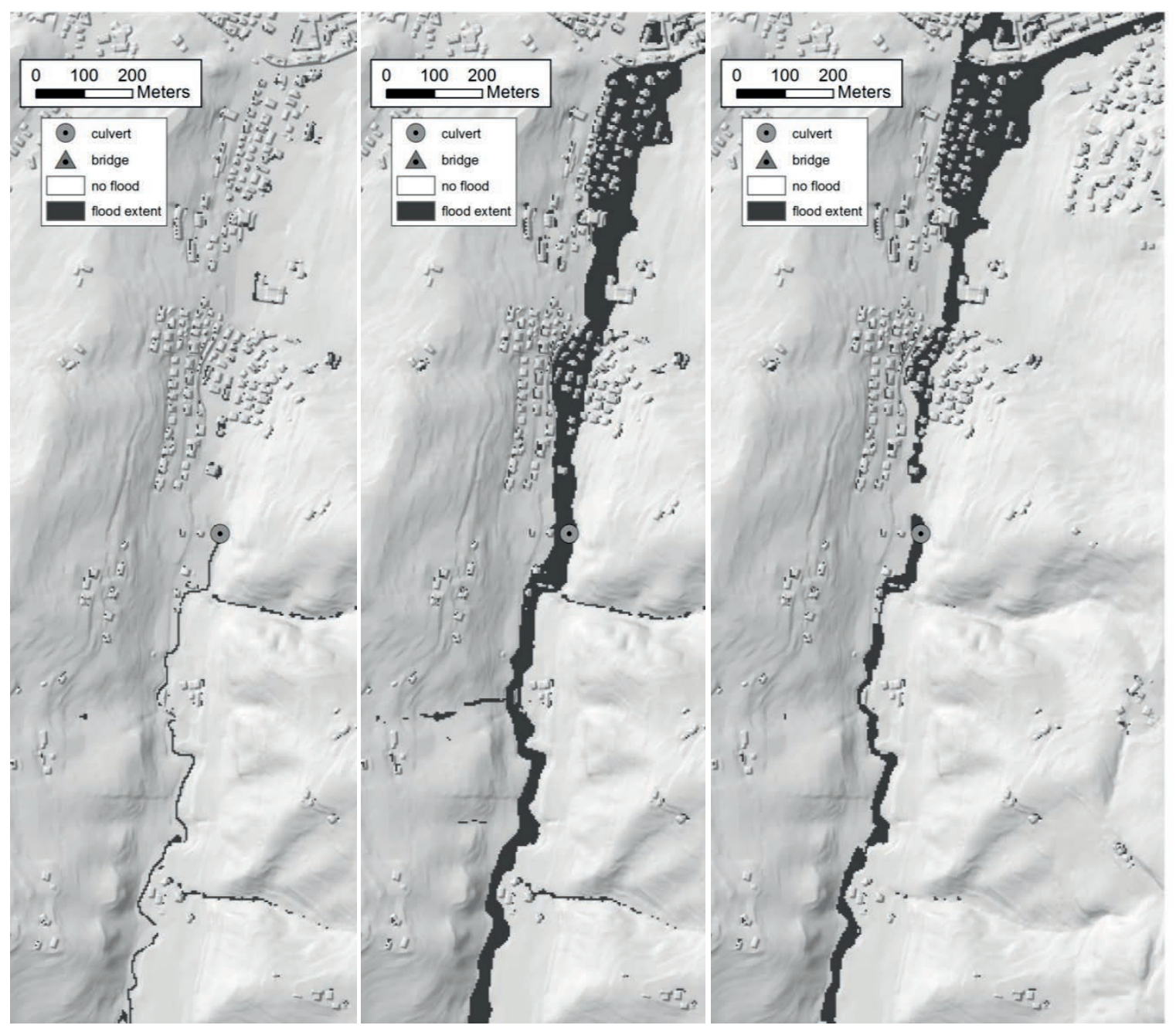

Fig. 3 Results of historical scenario. Flood extent (dark grey) in the lower part of the catchment at time $t$ $=30$ minutes (left), $\mathrm{t}=90$ minutes (centre), $\mathrm{t}=150$ minutes (right). The small black circle indicates the culvert entry.

\section{CONCLUSIONS}

In this work, a 2D hydraulic model has been applied to reproduce rainfall-runoff processes in the small urbanized catchment of the Ravone stream, with the aim of simulating the effects of historical rainfall scenarios in the present catchment configuration. Model results suggest that the vulnerability of the urbanized areas to flash flood events has significantly increased during the last 50 years, due to the increased urbanization, and the replacement of the natural stream bed with a culvert. According to simulations, a failure of the culvert section could occur in the case of intense events, causing the inundation of surrounding and downstream urban areas. 
The present study should be regarded as a preliminary analysis, aimed at testing the potential of a 2D modelling approach for analysing flash flood risk. In fact, the analyses carried out are based on several approximations while, to properly estimate flash flood hazard, more detailed hydrological analyses would be required to link extreme rainfall events and consequent runoff. In particular, a larger set of combined rainfall-runoff observed data are needed to analyse the hydrological processes and to calibrate model parameters. This issue will be addressed in the future, through the installation of a depth-gauge in the stream bed. In addition, the use of a variable resolution in the model grid would improve the model performance in terms of run-time. Finally, if data for describing the sewer system and the main culvert were available, then the catchment urban area could also be included in the analysis.

Despite the limitations of the present study, the results suggest that the use of simple 2D hydraulic models can be a valid method for defining dangerous rainfall scenarios and assessing the risk related to flash flood events in small catchments. In particular, the combination of a raingauge network with reliable rainfall-runoff modelling would enable the setting up of an early warning system based on rainfall measurement.

\section{REFERENCES}

Costabile, P. Costanzo, C. and Macchione, F. (2013) A storm event watershed model for surface runoff based on 2D fully dynamic wave equations. Hydrol. Processes 27, 554-569.

Dottori, F. and Todini, E. (2011) Developments of a flood inundation model based on the cellular automata approach: testing different methods to improve model performance. Physics and Chemistry of the Earth 36, 266-280.

Dottori, F. and Todini, E. (2013) Testing a simple 2D hydraulic model in an urban flood experiment. Hydrol. Processes 27(9), 1301-1320.

Hapuarachchi, H. A. P. Wang, Q. J. and Pagano, T. C. (2011) A review of advances in flash flood forecasting. Hydrol. Processes $25,2771-2784$

Singh, V. P. (2003) Soil Conservation Service Curve Number (SCS-CN) Methodology (Vol. 42). Springer. 